\title{
Side to side comparison of topical treatment in atopic dermatitis
}

\author{
P F Ainley-Walker, L Patel, T J David
}

\begin{abstract}
Objectives-To document and evaluate the outcome of side to side comparisons of different corticosteroids in determining the most effective topical treatment for individuals admitted to hospital for control of atopic dermatitis.

Methods-Retrospective case note study of 82 admissions (66 children) to a children's hospital for treatment of atopic dermatitis between 1 June 1993 and 31 October 1995. Different topical corticosteroid ointments were applied to the two sides of the body. The outcome measure was a comparison between the two sides, to see whether one treatment was better than the other.

Results-More potent topical corticosteroid preparations appeared more effective than weaker preparations on 25 occasions, there was no difference on 20 occasions, and on seven occasions a weaker preparation appeared more effective. Incorporation of an antimicrobial agent did not appear to increase the efficacy of a preparation.

Conclusions-The management of atopic dermatitis is bedevilled by considerable spontaneous fluctuations in severity, leading to uncertainty as to whether a new treatment is beneficial; a coincidental flare up of the skin lesions may be wrongly attributed to a particular treatment, which is then discarded. Comparing different topical treatments simultaneously on opposite sides of the body is a feasible and rational way to determine the optimum treatment for an individual with atopic dermatitis.

(Arch Dis Child 1998;79:149-152)
\end{abstract}

Keywords: atopic dermatitis; corticosteroids; topical corticosteroids

Department of Child Health, University of Manchester, Manchester, UK

P F Ainley-Walker

L Patel

T J David

Correspondence to: Professor T J David University Department of Child Health, Booth Hall Children's Hospital, Charlestown Road, Blackley, Manchester M9 7AA, UK. e-mail: tim.david@ dial.pipex.com

Accepted 24 April 1998

Once relevant trigger factors have been identified and where possible eliminated, the main treatment of atopic dermatitis is the topical application of emollients and corticosteroids. Whereas chronic conditions such as hypertension, diabetes, hypothyroidism, asthma or short stature can be managed by reference to relatively simple, reliable, and objective clinical or laboratory measurements, there is no such marker in atopic dermatitis. The management of atopic dermatitis is further bedevilled by considerable day to day and even minute to minute variation. Skin lesions that are quiescent at 08:00 can become highly inflamed by 09:00 after a journey in a hot car, a confronta- tion with a parent, the ingestion of a trigger food or, most commonly of all, for no apparent reason. Thus, there is often uncertainty as to whether a change in treatment is beneficial. In particular, there is a risk that a coincidental flare up of the skin lesions may be wrongly attributed to a particular treatment, which is then discontinued.

Side to side comparisons have been used in clinical trials of various topical treatments, mainly in psoriasis. ${ }^{1-10} \mathrm{~A}$ fundamental principle of this approach is that it can only be used when skin lesions are relatively symmetrical, as is commonly the case in atopic dermatitis. We have used side to side comparison when introducing new topical treatments to inpatients with atopic dermatitis, and this study aimed to document and evaluate the outcome of these comparisons.

\section{Subjects and methods}

We admit two categories of patient with atopic dermatitis to hospital, those with severe acute flare ups that cannot be controlled at home, and those with poorly controlled severe and chronic skin lesions. The management of the latter group routinely comprises side to side comparisons of different topical preparations. The side to side treatment comparison method incorporates the following principles.

- An overall aim to find the most suitable topical corticosteroid for continuing use; we do not use the strategy of starting with a very potent corticosteroid and then switching to a weaker preparation

- To treat the face and neck separately from the rest of the body, dividing it into left and right portions, never applying a corticosteroid stronger than mild potency

- To divide the rest of the body into four quadrants, ensuring that one quadrant is treated as a control with emollient only but no corticosteroid, to detect changes in the overall condition

To allow the free use of one emollient ointment or cream preparation (as preferred by the patient), with the exception that emollients are not applied to all areas of skin treated with topical corticosteroids up to two hours before or two hours after the application of corticosteroids

- To continue with the same frequency of bathing used before starting side to side comparisons

- To compare different topical corticosteroid preparations, usually from a different potency category (mildly potent, moderately potent, potent, and very potent, as defined in the British National Formulary ${ }^{11}$ 
- Where there was a history of recurrent secondary bacterial infection of the skin lesions, to include comparison of corticosteroid preparations with and without an antibacterial agent.

In this study, as in our standard practice, ${ }^{12} 13$ topical corticosteroids were always used as ointment and not as cream preparations.

Patients were assessed daily by either a registrar or a consultant who were aware of the treatments being compared but were blinded as to which area was being treated with a specific preparation. As part of the daily patient assessment, the observer made a comparison between the two sides. The main features assessed were the degrees of inflammation and erythema. Patients were discharged using either the most effective corticosteroid or, if there was no difference, using the weakest corticosteroid, or to try one or more different corticosteroid ointments.

We studied the medical records of all patients admitted and treated in this way between 1 June 1993 and 31 October 1995. All patients fulfilled the diagnostic criteria for atopic dermatitis of Hanifin and Rajka ${ }^{14}$ and the UK working party on diagnostic criteria for atopic dermatitis. ${ }^{15}$ We estimated body surface area affected by atopic dermatitis using modified charts for calculating the areas of burns in children, ${ }^{16}$ and classified as $<10 \%, 10-50 \%$, or $>50 \%$. Details of preadmission treatment regimens, treatment prescribed during admission, and outcome of treatment were recorded.

The McNemar test was used to compare the effects of mild potency topical corticosteroids with emollients, more potent topical corticosteroid preparations with less potent preparations, and topical corticosteroid preparations containing antimicrobial agents with preparations not containing antimicrobial agents. The $\mathrm{McNemar}$ test compares paired data where the variable under examination is binary. Significance was accepted at $\mathrm{p}<0.05$.

\section{Results}

Sixty six children ( 36 boys, 30 girls; aged 0.25 to 16 years, median 5 years) were studied during 82 admissions to hospital. Children were admitted for 1 to 24 days (median 5 days). For most admissions (55 of 82 ) the children had $>50 \%$ of their skin surface area affected by atopic dermatitis, for 24 admissions, 10-50\% of the skin surface area was affected, and for three admissions, $<10 \%$ was affected.

Before admission, an emollient ointment or cream had been used by 64 of 82 cases, 63 were using topical corticosteroids on the face and 75 were using topical corticosteroids on some other part of the body. On the face, antimicrobial agents (comprising clioquinol, fusidic acid, nystatin, gramicidin, oxytetracycline, neomycin, chlorquinaldol) were incorporated in the preparation in 26 of 59 mildly potent topical corticosteroids, one of the moderately potent corticosteroids, and both of the potent corticosteroids. On the body, antimicrobial agents were incorporated in the preparation in 12 of 26 mildly potent topical corticosteroids, nine of 28 moderately potent corticosteroids, and 12 of 21 potent corticosteroids. A sedating antihistamine had been prescribed for bedtime use in 53 of 82 cases. The agent used was trimeprazine in all but seven children, who were prescribed other sedating antihistamines (hydroxyzine, promethazine, chlorpheniramine, azatadine, methotrimeprazine).

In 28 of 82 admissions, children were using inhaled $\beta_{2}$ agonists for asthma; 23 of these children were also using inhaled corticosteroids. Five patients were on long term oral corticosteroids: beclomethasone for atopic dermatitis (two cases) $)^{17}$ and prednisolone (for atopic dermatitis in one case and for asthma in two cases). Emollients were used in 81 of 82 admissions. The sedative $\mathrm{H} 1$ receptor antagonist trimeprazine was given at bedtime during 73 of 82 admissions.

\section{CORTICOSTEROID $v$ EMOLLIENT}

We compared a topical corticosteroid with an emollient alone on 22 occasions in 20 children, 10 of whom were newly referred. We compared a mildly potent corticosteroid (1\% hydrocortisone ointment) with emollient on 17 of 22 occasions. The corticosteroid appeared more effective in 10 of the 17 cases, there was no difference between the two preparations in five cases, and the emollient appeared more effective in two cases $\left(\chi^{2}=5.33\right.$, df 2 , $\mathrm{p}<0.05)$. A moderately potent topical corticosteroid was compared with an emollient in three of 22 cases. The corticosteroid appeared more effective in one comparison, but in the other two cases there was no difference. A potent topical corticosteroid was compared with emollient alone in two cases and in both the corticosteroid appeared more effective.

\section{CORTICOSTEROID $v$ CORTICOSTEROID COMBINED} WITH ANTIBACTERIAL AGENT

Forty two comparisons involved topical corticosteroids of the same potency, with or without an antibacterial agent. We found no difference between the two types of preparation in 23 comparisons; the corticosteroid with an antibacterial agent appeared more effective in 11 cases; and corticosteroid alone appeared more effective in eight cases $\left(\chi^{2}=0.47\right.$, df 1 , $\mathrm{p}>0.05)$.

\section{MILDLY $v$ MODERATELY POTENT}

CORTICOSTEROIDS

There were 31 comparisons of mildly $v$ moderately potent corticosteroids. The mildly potent corticosteroid appeared more effective in five cases; there appeared to be no difference in 10 cases; and the moderately potent corticosteroid appeared more effective in 16 comparisons. A moderately potent topical corticosteroid was significantly more effective than a mildly potent corticosteroid $\left(\chi^{2}=5.76\right.$, df 2 , $\mathrm{p}<0.05)$.

MILDLY POTENT $v$ POTENT CORTICOSTEROIDS There were nine comparisons of mildly potent $v$ potent corticosteroids. In six we could detect no difference, and in three the potent corticosteroid appeared to be more effective. 
MODERATELY POTENT $v$ POTENT TOPICAL CORTICOSTEROIDS

There were 12 comparisons of moderately potent $v$ potent corticosteroids. We could detect no difference in four cases. In six the potent corticosteroid appeared more effective, and in two we considered the moderately potent corticosteroid more effective. A potent topical corticosteroid was not more effective than a moderately potent corticosteroid $\left(\chi^{2}=2.0\right.$, df $\left.1, \mathrm{p}>0.05\right)$.

COMPARISONS OF DIFFERENT BUT EQUIPOTENT CORTICOSTEROIDS

There were 10 comparisons of different, equipotent corticosteroids. We detected no difference in four cases, but in six one preparation appeared more effective than the other.

\section{Discussion}

There are a number of methodological drawbacks to this study. It was retrospective, and therefore dependent on the amount of information recorded routinely. The need to include the patient's original medication prevented complete standardisation, so that several different combinations of topical treatments were compared, leading to small numbers in some comparisons. The lack of an objective measure of local disease severity is a difficulty that applies to any clinical study of atopic dermatitis. The fact that the patients were referred and admitted implies they were a highly selected and a severe subset of the general population of patients with atopic dermatitis. An advantage of such a group is that compliance is more likely to be achieved during the study period. Admission to hospital is itself a confounding variable, because atopic dermatitis sometimes improves when patients are admitted, even without any change of treatment. One reason for maintaining one quadrant without corticosteroid treatment was to detect overall improvement, either as a non-specific result of admission or as a result of treatment with an oral antibiotic. However, factors leading to overall improvement would not account for differences between two sides of the body.

To compare treatments on opposite sides of the body successfully, it is important to prevent mixing of the different preparations and cross contamination. Nurses applied topical agents. They wore disposable gloves, and changed them before applying a new preparation. However, if the treatments were to be applied by a parent or an older child at home, it is possible that they would be less careful. In theory, clothing could allow some degree of spread of topical medication on the trunk, making interpretation more difficult.

The effectiveness of topical corticosteroids depends not only on the intrinsic potency of the corticosteroid molecule, but also on factors such as the vehicle and ability of the molecule to penetrate the epidermis. ${ }^{19}{ }^{20}$ The greater potency of a corticosteroid ointment does not necessarily imply greater therapeutic efficacy.

Although emollients are widely recommended in the management of atopic dermatitis, their benefit has never been proved in con- trolled trials. It is therefore of some interest to note that in seven of 21 comparisons between emollient and topical corticosteroid there was no apparent difference, and the emollient appeared more effective in two cases. A similar observation has been made before in adults with chronic hand dermatitis in whom an emollient containing no active ingredients was as effective as $0.025 \%$ betamethasone valerate (a potent corticosteroid) over a one month period. ${ }^{21}$ It is possible that apparently bland emollients have pharmacological propertiesfor example, studies in mice have demonstrated that the "placebo" effect of topical applications such as white soft paraffin or cetomacrogol cream results in part from antimitotic activity. ${ }^{22}$ In addition, some bland preparations have an anticyclo-oxygenase effect on the microsomal fraction of skin homogenates ${ }^{23}$ and this could account for many of the anti-inflammatory effects of these materials. Certain emollients, such as white soft paraffin, have been shown to have vasoconstrictor activity in the skin (to a lesser degree than topical corticosteroids) as well as a skin thinning effect (also to a lesser degree than topical corticosteroids). ${ }^{24}$

It is known that the stratum corneum layer of the skin can act as a reservoir for topically applied corticosteroids. In healthy skin, this reservoir may last for a few days, ${ }^{25}{ }^{26}$ but in eczematous skin the effect may only last for one or two days. ${ }^{27}$ Either systemic absorption or a reservoir effect might help to explain some of the cases where corticosteroid and emollient were equally effective, because the patients had been using topical corticosteroids on their skin before admission in six of the nine cases. However, a reservoir effect cannot explain the apparent equal efficacy of corticosteroid and emollient in the three children who had not been using topical corticosteroids before admission to hospital. Lastly, in cases where there was no apparent advantage of corticosteroid over emollient, it is theoretically possible that the topical corticosteroid caused worsening of the skin condition, either by irritation from the excipients or by causing contact dermatiti ${ }^{28-30}$; however, we found no evidence of these types of worsening in these cases.

Comparing different topical agents simultaneously on opposite sides of the body is a feasible and rational way to determine the best topical treatment for an individual with atopic dermatitis. Differences are often visible within a very short period (1-2 days). This is in keeping with previous observations of very rapid improvement following the introduction of topical corticosteroid treatment. ${ }^{31}$ The approach is consistent with the overall goal of trying to find the treatment that is best suited to an individual patient. However, the hypothesis that demonstrating efficacy to patients and parents leads to improved adherence to treatment or to a better outcome is as yet untested.

We thank Professors P S Friedmann and K Thestrup-Pedersen for their helpful advice.

1 Sulzberger MB, Witten VH. The effect of topically applied compound $\mathrm{F}$ in selected dermatoses. F Invest Dermatol 1952;19:101-2. 
2 Kragballe K, Gjertsen BT, De Hoop D, et al. Double-blind, right/left comparison of calcipotriol and betamethasone valerate in treatment of psoriasis vulgaris. Lancet 1991;337: 193-6.

3 Kragballe K, Larsen FG. A hydrocolloid occlusive dressing plus triamcinolone acetonide cream is superior to clobetasol cream in palmo-plantar pustulosis. Acta Derm Venereol 1991;71:540-2.

4 Kragballe K, Dam TN, Hansen ER, et al. Efficacy and safety of the 20-epi-vitamin D3 analogue KH 1060 in the topical therapy of psoriasis: results of a dose-ranging study. Acta Derm Venereol 1994;74:398-402.

5 Williamson DM. Comparison of a modified hydrocortisone/ urea cream and betamethasone valerate cream in the treatment of dry eczema. F Int Med Res 1987;15:99-105.

6 Munkvad M. A comparative trial of Clinitar versus hydrocortisone cream in the treatment of atopic eczema. $B r$ f Dermatol 1989;121:763-6.

7 Tham SN, Lun KC, Cheong WK. Comparative study of calcipotriol ointment and tar in chronic plaque psoriasis. $\mathrm{Br}$ calcipotriol ointment and tar in

8 Kragballe K, Beck HI, Sogaard H. Improvement of psoriasis by a topical vitamin D3 analogue (MC 903) in a double-blind study. Br F Dermatol 1988;119:223-30.

9 Wendt H, Mugglestone CJ, Wiseman RA. A study of the comparative efficacy of diflucortolone valerate $0.3 \%$ ointment and clobetasol propionate $0.05 \%$ ointment. $\mathrm{Br} \mathcal{F}$ Dermatol 1978;99:411-16.

10 Tazelaar DJ. Tibicorten and betamethasone valerate: a double-blind comparative study. F Int Med Res 1977;5:33845.

11 British National Formulary. Number 35 (March 1998). London: British Medical Association and Royal Pharmaceutical Society of Great Britain, 1998.

12 David TJ. Atopic eczema. Prescribers f 1995;35:199-205.

13 David TJ, Devlin J, Ewing CI. Atopic and seborrheic dermatitis: practical management. Pediatrician 1991;18: 211-17.

14 Hanifin JM, Rajka G. Diagnostic features of atopic dermatitis. Acta Derm Venereol 1980;(suppl 92):44-7.

15 Williams HC, Burney PJ, Hay RJ, et al. The UK working party's diagnostic criteria for atopic dermatitis. I. Derivaparty's diagnostic criteria for atopic dermatitis. I. Derivation of a minimum set of discriminat
titis. Br f Dermatol 1994;131:383-96.

16 Lund CC, Browder NC. The estimation of areas of burns. Surg Gynecol Obstet 1944;79:352-8.
17 Heddle RJ, Soothill JF, Bulpitt CJ, Atherton DJ. Combined oral and nasal beclomethasone diproprionate in children with atopic eczema: a randomised controlled trial. $B M F$ 1984;289:651-4.

18 Aylett SE, Atherton DJ, Preece MA. The treatment of diffcult atopic dermatitis in childhood with oral beclomethasone dipropionate. Acta Derm Venereol 1992;(suppl 176): 123-5.

19 Wester RC, Maibach HI. Percutaneous absorption of topical corticosteroids. Curr Prob Dermatol 1993;21:45-60.

20 Hepburn D, Yohn JJ, Weston WL. Topical steroid treatment in infants, children, and adolescents. Adv Dermatol 1994;9: 225-55.

21 Marks R. Topical steroids. Lancet 1977;ii:758.

22 Tree S, Marks R. An explanation for the "placebo" effect of bland ointment bases. Br F Dermatol 1975;92:195-8.

23 Penneys NS, Eaglestein W, Ziboh V. Petrolatum: interference with the oxidation of arachidonic acid. Br f Dermatol 1980;103:257-62.

24 Marks R. Effects of emollients on inflammatory dermatoses. In: Frost P, Hurwitz SN, eds. Principles of cosmetics for the dermatologist. St Louis: CV Mosby, 1982:334-6.

25 Vickers CFH. Existence of reservoir in the stratum corneum. Experimental proof. Arch Dermatol 1963;88:725.

26 Feldmann RJ, Maibach HI. Penetration of 14C hydrocortisone through normal skin. The effect of stripping and occlusion. Arch Dermatol 1965;91:661-7.

27 Turpeinen M. Absorption of hydrocortisone from the skin reservoir in atopic dermatitis. Br F Dermatol 1991;124:35860 .

28 Wilkinson SM, Cartwright PH, English JSC. Hydrocortisone: an important cutaneous allergen. Lancet 1991;337:761-2

29 Korting HC, Maibach HI. Contact allergy to topical glucocorticoids. Curr Probl Dermatol 1993;21:170-9.

30 Dooms-Goossens A, Meinardi MMHM, Bos JD, Degreef $\mathrm{H}$. Contact allergy to corticosteroids: the results of a two-centre study. Br 7 Dermatol 1994;130:42-7.

31 Schachner LA. A 3-day rate of efficacy of a moderate potency topical steroid in the treatment of atopic dermatitis in infancy and childhood. Pediatr Dermatol 1996;13: 513-14. 